January 2001

\title{
Hemoglobin concentration in children in a malaria holoendemic area is determined by cumulated Plasmodium falciparum parasite densities
}

H. Ekvall

Karolinska Hospital

Zul Premji

Aga Khan University, zul.premji@aku.edu

S. Bennett

London School of Hygiene and Tropical Medicine

A. Bjorkman

Karolinska Hospital

Follow this and additional works at: http://ecommons.aku.edu/eastafrica_fhs_mc_pathol Part of the Pathology Commons

\section{Recommended Citation}

Ekvall, H., Premji, Z., Bennett, S., Bjorkman, A. (2001). Hemoglobin concentration in children in a malaria holoendemic area is determined by cumulated Plasmodium falciparum parasite densities. American Journal of Tropical Medicine and Hygiene, 64(2014-01-02), 58-66.

Available at: http://ecommons.aku.edu/eastafrica_fhs_mc_pathol/86 


\title{
HEMOGLOBIN CONCENTRATION IN CHILDREN IN A MALARIA HOLOENDEMIC AREA IS DETERMINED BY CUMULATED PLASMODIUM FALCIPARUM PARASITE DENSITIES
}

\author{
HAKAN EKVALL, ZUL PREMJI, STEVE BENNETT, AND ANDERS BJORKMAN \\ Unit of Infectious Diseases, Karolinska Institute, Karolinska Hospital, Stockholm, Sweden; Department of Parasitology and \\ Entomology, Muhimbili University College of Health Sciences, Dar es Salaam, Tanzania; Department of Infectious and Tropical \\ Diseases, London School of Hygiene and Tropical Medicine, London, United Kingdom
}

\begin{abstract}
In malaria holoendemic areas children are anemic, but the exact influence of falciparum malaria on hemoglobin $(\mathrm{Hb})$ concentration remains largely unsettled. Prospective data were therefore collected in children $<24$ months of age during five months in a Tanzanian village. Children with mean asymptomatic parasitemia $\geq 400 / \mu 1$ had lower median Hb levels during the study than those with mean density $<400 / \mu l$. The difference was $9.7 \mathrm{~g} / \mathrm{L}$ (95\% confidence interval [CI] 2.8-17). In children with one or more clinical malaria episodes, the median $\mathrm{Hb}$ was $8.3 \mathrm{~g} / \mathrm{L}$ (95\% CI 0.9-16) lower than those without episode. If early treatment failure was recorded, the immediate effect on $\mathrm{Hb}$ was particularly important with a mean drop of $17 \mathrm{~g} / \mathrm{L}$. Interestingly, at study-end the Hb concentration represented a function of the area under the parasitemia curve (AUPC) during the previous five months, adjusting for age. In conclusion, stepwise deterioration in median $\mathrm{Hb}$ levels was found by asymptomatic parasitemia, clinical malaria episode, and most significantly, treatment failure.
\end{abstract}

\section{INTRODUCTION}

In sub-Saharan Africa, morbidity and mortality from childhood anemia are severe public health problems. ${ }^{1}$ The main contributory causes of anemia are infectious diseases, nutritional disorders, and hemoglobinopathies. ${ }^{2}$ Some investigators cite an iron-deficient diet, hookworm infection, or schistosomiasis as important causes for anemia, ${ }^{3-5}$ while others have identified malaria as the primary cause. Cross-sectional data have shown deterioration in hemoglobin $(\mathrm{Hb})$ concentration during malaria transmission and an improvement in $\mathrm{Hb}$ with the administration of malaria chemoprophylaxis or insecticide-treated bed nets. ${ }^{6-8}$ These studies do not fully exclude other conditions associated with malaria, but Plasmodium falciparum infection appears to be a major factor in $\mathrm{Hb}$ change. ${ }^{9}$

During infancy, acute malaria episodes have consistently been associated with low hematocrit $<25 \%,{ }^{10}$ mainly occurring from four months of age when children are at risk of clinical attacks. ${ }^{11,12}$ However, malaria-associated anemia may also develop without fever, and be undiagnosed as clinical malaria requiring treatment. ${ }^{13}$ It has therefore been suggested that children aged $<36$ months living in an area with $P$. falciparum malaria should be routinely treated for malaria if they have signs of anemia. ${ }^{14}$

The causal relationship between $P$. falciparum parasitemia and $\mathrm{Hb}$ concentration in malaria-holoendemic areas is difficult to establish since most children continually harbor parasites. ${ }^{15}$ Furthermore, the impact on $\mathrm{Hb}$ of clinical episodes and asymptomatic long-term parasitemia may be difficult to distinguish. ${ }^{16}$ Cross-sectional data or data from hospitalized children with severe anemia are unable to capture the dynamic relationship between malaria and anemia, ${ }^{17-19}$ and only longitudinal data may reveal whether a low $\mathrm{Hb}$ level is the result of recent high parasite density or of longstanding parasitemia. ${ }^{20}$ Furthermore, the pathophysiologic processes of anemia in malaria include both hemolytic destruction of erythrocytes and bone marrow suppression, ${ }^{21}$ implying different time-lags between parasitemia and subsequent effects on $\mathrm{Hb}$ levels, ${ }^{22}$ and hence the need for prospective data.
The objective of the present study was to prospectively investigate the impact of symptomatic and asymptomatic parasitemias on $\mathrm{Hb}$ levels in children living in a rural area with holoendemic malaria.

\section{PATIENTS AND METHODS}

Study design. Data for the present study were collected from a prospective cohort of 211 Tanzanian children participating in a randomized controlled intervention trial documenting the effects of regular micronutrient supplementation on malaria and anemia. ${ }^{23}$ Descriptive data of the whole cohort are presented below, but analyses have been restricted to the 103 subjects from the placebo group.

The study was conducted from June to November 1995 in Fukayosi village, $30 \mathrm{~km}$ west of Bagamoyo town, coastal Tanzania. Malaria is holoendemic and transmission is perennial with a seasonal peak in July. A census of all children aged between five and 36 months was performed by members of the village committee, and 211 out of 220 children enumerated were enrolled. No child had to be excluded due to congenital malformations, clinically decompensated anemia, or migration plans, but four subjects did not participate in the randomized controlled trial due to having an initial $\mathrm{Hb}$ concentration $<50 \mathrm{~g} / \mathrm{L}$. Informed consent was obtained from all parents for 20 weeks' follow-up and randomization of the intervention. On enrollment, all children received an identity number and a "Mother-and-Child-Health" card. Demographic data, including age, were obtained from the card held by each child's parent, and the approximate distance from their home to the village dispensary was estimated by fieldworkers after the start of the study. A medical examination, including weight, spleen size, and axillary temperature, was made by one of the investigators and capillary blood was collected for thick blood films and hematological measurement. Any history of traditional uvulectomy was elicited as this could affect $\mathrm{Hb}$ concentration.

The children were seen every second week by the research team at the village dispensary for medical examination and axillary temperature measurement. These 11 dispensary vis- 
its, including baseline and end surveys, constituted the active case detection. In addition, six team workers made home visits three times a week which equaled 56 occasions per child for supervised administration of placebo or supplement. Any child with a febrile history would then be referred to the dispensary ("actively passive" case detection). Finally, for passive case detection of fever episodes, the village dispensary was staffed around-the-clock by an assistant doctor and nurse from the team, and daily by at least one of the principal investigators. Study participation was recorded both at the bi-weekly dispensary examinations and during the regular home visits on alternate days. Activities of all team members were continually supervised by the principal investigators.

Clinical malaria episodes. A standardized medical examination was performed in all children with an axillary temperature $\geq 37.5^{\circ} \mathrm{C}$. This included symptoms and signs of diseases other than malaria, as well as an estimation of the clinical severity of the current episode. Capillary blood was collected for immediate preparation and examination of a thick blood film, with an additional $40 \mu \mathrm{l}$ pre-diluted for hematological measurements including $\mathrm{Hb}$ concentration. The pre-diluted specimens were transported by car in a coolbox for approximately one hr before being analyzed. Results were available at the dispensary the next day. Fever episodes judged to be non-malarial in origin were treated accordingly; co-trimoxazole was not used as an antibiotic due to its antimalarial effect. After clinically excluding other febrile conditions, a $P$. falciparum parasite density $>4,000$ asexual parasites per $\mu$, estimated during the immediate slide examination in the field was considered indicative of a clinical malaria episode requiring treatment.

Malaria episodes were treated with chloroquine syrup (Elyquine ${ }^{\circledR}$ by Elys Ltd, Dar es Salaam, Tanzania) in accordance with Ministry of Health guidelines and administered by a team nurse. Ten $\mathrm{mg} / \mathrm{kg}$ of chloroquine base was given on Day 0 , followed by $10 \mathrm{mg} / \mathrm{kg}$ on Day 1 , and five $\mathrm{mg} / \mathrm{kg}$ on Day 2. Every intake was supervised and children were subsequently observed at the dispensary for $20 \mathrm{~min}$. In case of vomiting, a full dose was repeated and the child observed as before. Axillary temperature was measured daily until Day 3.

Routinely, capillary blood was collected again on Day 3 for thick blood films and hematologic measurement. In case of persistent fever on Day 2, or clinical deterioration before Day 3, the child was re-evaluated and blood collected for hematologic and immediate parasitologic examination; children with early treatment failure were given sulfadoxinepyrimethamine (SP) and referred to the district hospital, if necessary. All in-hospital drugs for study children were provided by the team. Late clinical treatment failures with fever and parasitemia reappearing between Days 4-13 were treated with SP and paracetamol. Recurrence of clinical malaria episodes from Day 14 were assumed to be due to re-infection and treated as new episodes. All new resumptions of fever during the 20 weeks' follow-up were recorded, classified, and treated as described.

Classification of therapeutic response. Therapeutic response within the first 14 days of treatment was defined according to World Health Organization (WHO) guidelines. ${ }^{24}$ However, since subjects' adherence to the study protocol did not allow capillary blood collection frequently enough, a modification was made. Early treatment failure (ETF) was defined according to the WHO (1996) document, but late treatment failure (LTF) or adequate clinical response (ACR) was based on blood and clinical examinations performed two to four weeks after treatment at the regular dispensary visit on or next after Day 14.

Early treatment failure was defined by the following criteria:

- Danger signs (unconsciousness, prostration, convulsion, excessive vomiting, or no oral intake) within $72 \mathrm{hr}$, and asexual $P$. falciparum parasitemia.

- Temperature $\geq 37.5^{\circ} \mathrm{C}$ after $48 \mathrm{hr}$, with asexual parasitemia $>$ Day 0.

- Temperature $\geq 37.5^{\circ} \mathrm{C}$ after $72 \mathrm{hr}$ with asexual parasitemia.

- Asexual parasitemia after $72 \mathrm{hr} \geq 25 \%$ of Day 0 .

Late treatment failure was defined as:

- Danger signs and asexual parasitemia during Days 4-14, without meeting the criteria for ETF.

- Temperature $\geq 37.5^{\circ} \mathrm{C}$ and asexual parasitemia during Days 4-14, without meeting the criteria for ETF.

Adequate clinical response was defined as:

- Temperature $<37.5^{\circ} \mathrm{C}$ with asexual parasitemia during Days 15-28, without meeting the criteria for ETF or LTF.

- No asexual parasitemia during Days 15-28, without meeting the criteria for ETF or LTF.

Scheduled blood collections. Blood samples were drawn from all children at the baseline and end surveys and in two surveys after approximately two and four months. Capillary blood was also collected twice during each clinical malaria episode and once at follow-up. All collections included a blood slide and $\mathrm{Hb}$ estimation.

Laboratory tests and quality control. Thick blood films were stained with 5\% Giemsa stain, and the asexual parasite density was estimated by counting parasites against 200 white blood cells (WBC), assuming a standard WBC count of $8,000 / \mu 1 .{ }^{25}$ If less than 10 parasites were recorded per 200 leucocytes, estimation was made against another 300 WBCs. All P. falciparum parasitemias, whether single or dual infections, were used in the analyses. The slides of febrile patients were first examined in the field. All slides were later read by the investigator who examined all blood slides, with $10 \%$ re-checked by two blinded, independent microscopists. The between-reader variability of parasite density was $<1.5$ $\log$.

For hematologic measurements, an automated hematologic analyser (Cell-Dyn ${ }^{\circledast}$ 610, Abbot Laboratories) was used. Daily commercial quality controls assessed the coefficient of variation for the within-sample precision of the $\mathrm{Hb}$ estimate at $<1 \%$, both for immediate run samples and after a sixhour delay in analysis. Capillary blood collection was standardized to prevent pre-analytic bias in $\mathrm{Hb}$ estimation. All fingerprick specimens were collected during morning hours, if possible. The children were sitting upright in their mothers' laps, allowing free flow of capillary blood. Two team members performed all blood collections.

Screening was performed for conditions potentially af- 
TABLE 1

Descriptive data from baseline and end surveys by age

\begin{tabular}{|c|c|c|c|c|c|}
\hline Age group* & Survey & $\begin{array}{l}\text { Mean Hb } \\
\text { g/L (SD) }\end{array}$ & $\begin{array}{c}\mathrm{Hb}<70 \mathrm{~g} / \mathrm{L} \\
\text { No. }(\%)\end{array}$ & $\begin{array}{c}\text { Parasitemic children } \\
\text { No. }(\%)\end{array}$ & 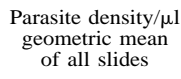 \\
\hline$<24$ months & Baseline & 80 (14) & $16 / 46(35 \%)$ & $43 / 46(94 \%)$ & 3,100 \\
\hline$<24$ months & End & 88 (14) & $6 / 43(14 \%)$ & $35 / 43(81 \%)$ & 670 \\
\hline$\geq 24$ months & Baseline & 97 (14) & $1 / 57(2 \%)$ & $50 / 57(88 \%)$ & 920 \\
\hline$\geq 24$ months & End & 96 (13) & $2 / 54(4 \%)$ & $49 / 54(91 \%)$ & 1,000 \\
\hline All & Baseline & 89 (16) & $17 / 103(16 \%)$ & $93 / 103(90 \%)$ & 1,620 \\
\hline All & End & 92 (14) & $8 / 97(8 \%)$ & $84 / 97(86 \%)$ & 840 \\
\hline
\end{tabular}

$*$ Age at study-end. $\mathrm{Hb}=$ hemoglobin; $\mathrm{SD}=$ standard deviation.

fecting anemia, but no children had to be excluded from the analyses. Sickle cell hemoglobin was assessed by a solubility test and confirmed by $\mathrm{Hb}$ electrophoresis. Human immunodeficiency virus (HIV) was investigated by enzyme-linked immunosorbent assay (ELISA) (Behring) and confirmed by Western blot. The HIV results were only available after study termination and were blinded; hence, no pre-test counseling was performed. Helminthic infections were investigated but not quantified in a single stool specimen by the formalin-ether concentration technique. ${ }^{26}$

Statistical methods. The data were analyzed using EpiInfo $^{\infty} 6.2$ and $\mathrm{JMP}^{\circledast} 3.1$ (SAS Institute Inc.). Clinical malaria incidence rates were calculated based on person-time attendance during home visits. Proportions were compared with the aid of Pearson's chi-square or Fisher's exact test. Paired or two-sample t-tests and analysis of variance were used for normally distributed continuous data; parasite densities were normalized after adding one to each count, using logarithmic transformation. The Wilcoxon rank-sum test was used for non-normal continuous data. A statistical significance level of 0.05 , two-tailed test, was generally employed.

Ethical considerations. All work was performed in accordance with the guidelines for human experimentation in clinical research stated in the research approval from the ethical committees of the Karolinska Institute in Stockholm and the Muhimbili College of Health Sciences in Dar es Salaam, Tanzania. Parents of study subjects provided oral informed consent.

\section{RESULTS}

Full cohort descriptives. Study subjects. The 211 children of the full study cohort had a mean age of 19 months (SD 8.5) at enrollment; $51 \%$ were male. The frequency of home-visit attendance revealed that $88 \%$ of the children's total person-time was observed and recorded in the study. Study participation was evenly distributed over the 20 study weeks and unaffected by distance from home to dispensary (data not shown). The median attendance at the regular biweekly dispensary examinations was $100 \%$, with 190 children $(90 \%)$ present at $\geq 8$ of the 11 scheduled visits. The 45 children living furthest away from the dispensary had a slightly lower attendance record with a median of $91 \%$ (interquartile range [IQR] 73-100).

Biochemical and clinical observations. Blood was collected on 1,540 occasions in the 211 study subjects, corresponding to a median of seven observations per child (range 1-19). A median of four (IQR 3-4) blood collections were made in children with no clinical malaria episodes recorded during the study. There was no fever or ongoing drug treatment at the time of $856(56 \%)$ blood collections. Out of all blood slides, 1,092 (73\%) were single infections with $P$. falciparum, $183(12 \%)$ were dual infections that included $P$. falciparum, and $14(1 \%)$ were single infections with another species. No child remained aparasitemic over the full study period.

Out of 388 fever episodes recorded during the five study months, 284 were diagnosed and treated as malaria episodes. Forty percent of fevers were detected at the scheduled biweekly visits and $60 \%$ upon reporting to the dispensary. A total of $103(36 \%)$ malaria cases were diagnosed in the first month; study onset coincided with peak malaria transmission at the end of the rainy season. The incidence of clinical malaria episodes subsequently dropped and remained constant over the subsequent four months.

During the study period, three children were referred to hospital due to gastroenteritis and malaria, and one of them received a blood transfusion. The children were continually followed during and after hospital admission. The prevalence of the sickle-cell trait was $23 \%$. No child was found positive for HIV infection. Hookworm infection was detected in $13 \%$ of the children, but there was no statistical association with $\mathrm{Hb}$ concentration, adjusting for age (data not shown).

Placebo group analyses. The following analyses on the relationship between parasitemia and $\mathrm{Hb}$ levels are based on data from the 103 children of the placebo group who did not receive micronutrient supplementation.

Age dependence. Data from the cross-sectional surveys at the beginning and end of the study are displayed in Table 1 . Children aged $<24$ months at study-end had initially significantly lower $\mathrm{Hb}$ and more often severe anemia, i.e., $\mathrm{Hb}$ $<70 \mathrm{~g} / \mathrm{L}$, than older children $(P<0.001)$, but this difference was less apparent at the end of study and not statistically significant for the prevalence of severe anemia $(P=0.11)$. There was also a statistically significant reduction in parasite prevalence and mean density in children $<24$ months over the five-month study period (Table 1 ). The longitudinal data presented in Table 2 revealed a marked age dependence of malaria indices, such as the clinical malaria incidence rate and parasite density at treatment onset. Early chloroquine treatment failure rate was also highest in the youngest children.

Clinical malaria episodes. The parasite density on Day 0 of first or only clinical malaria episode was linearly related to the subsequent drop in $\mathrm{Hb}$ after $72 \mathrm{hr}(P<0.001$; data 
TABLE 2

Clinical falciparum malaria episodes, treatment responses to chloroquine, and asymptomatic parasitemias by age

\begin{tabular}{|c|c|c|c|c|}
\hline & \multicolumn{4}{|c|}{ Age at study-end } \\
\hline & $<18$ months & $18-23$ months & $\geq 24$ months & All \\
\hline No. of children at baseline & 20 & 26 & 57 & 103 \\
\hline $\begin{array}{l}\text { Children with at least one clinical malaria } \\
\text { episode recorded, no. (\%) }\end{array}$ & $14(70 \%)$ & $21(81 \%)$ & $28(49 \%)$ & $63(61 \%)$ \\
\hline $\begin{array}{l}\text { Mean incidence rate of clinical malaria epi- } \\
\text { sodes/person-month }(95 \% \mathrm{CI})\end{array}$ & $0.38(0.24-0.52)$ & $0.29(0.19-0.39)$ & $0.16(0.11-0.22)$ & $0.24(0.19-0.29)$ \\
\hline $\begin{array}{l}\text { Parasite density/ } \mu 1 \text { at start of antimalarial } \\
\text { treatment, geometric mean (IQR) of all } \\
\text { episodes }\end{array}$ & $25,000(7,800-70,000)$ & $11,000(5,000-39,000)$ & $9,000(4,500-25,000)$ & $13,000(5,000-41,000)$ \\
\hline $\begin{array}{l}\text { Children with early treatment failure, no. } \\
(\%) \\
\text { Children with late treatment failure, no. }(\%)\end{array}$ & $\begin{array}{l}8(40 \%) \\
4(20 \%)\end{array}$ & $\begin{array}{l}3(12 \%) \\
5(19 \%)\end{array}$ & $\begin{array}{l}3(5 \%) \\
8(14 \%)\end{array}$ & $\begin{array}{l}14(14 \%) \\
17(17 \%)\end{array}$ \\
\hline $\begin{array}{l}\text { Asymptomatic parasite density/ } \mu 1 \text {, geometric } \\
\text { mean (IQR) }\end{array}$ & $610(400-5,000)$ & $1,000(530-6,300)$ & $740(600-5,000)$ & $790(500-5,000)$ \\
\hline
\end{tabular}

not shown). Early failure of chloroquine treatment was associated with an immediate reduction of $\mathrm{Hb}$ concentration within $72 \mathrm{hr}$, but this was only evident in the presence of hyperparasitemia (Table 3). The magnitude of the fall was unrelated to age, after adjusting for parasite density. Treatment failure was not associated with hyperparasitemia per se (data not shown). In 33 of 46 children $<24$ months the criteria for chloroquine treatment failure was not fulfilled at any time during the study. In these children, an increasing incidence of clinical malaria episodes was associated with a linear decline in individual median $\mathrm{Hb}$, from 88 to $64 \mathrm{~g} / \mathrm{L}$ $(P=0.03$; Figure 1$)$. The interactive effects of clinical malaria episodes, mean asymptomatic parasitemias, and number of negative blood-slides on individual median $\mathrm{Hb}$ levels are presented in Figure 2. In children $\geq 24$ months, hemoglobin levels were only marginally affected by clinical episodes and parasite densities (Figure 2B). In contrast, in children $<24$ months the effect was significant (Figure 2A), and those with at least one clinical malaria episode had $8.3 \mathrm{~g} / \mathrm{L}(95 \% \mathrm{CI}$, 0.9-16.0) lower median $\mathrm{Hb}$ than those without any episode.

Asymptomatic parasitemia. As seen in Table 2, the overall geometric mean parasite density during asymptomatic intervals and occurrence of negative blood-slides were not associated with age. This relationship was confounded, however, by SP treatment. Sulfadoxine-pyrimethamine treatment, mainly given to the youngest children, resulted in lower parasite density and prevalence in subsequent asymptomatic follow-up specimens; the geometric mean parasitemia in children treated with SP at any time during the study was 200 parasites/ $\mu l$ compared to 1,150 in children without such treatment $(P=0.003)$. As shown in Figure $2 \mathrm{~A}$, children $<$ 24 months with asymptomatic mean parasite density $\geq 400 /$ $\mu l$ had $9.7 \mathrm{~g} / \mathrm{L}$ (95\% CI 2.8-17.0) lower median Hb levels than those with mean density $<400 / \mu 1$. Similarly, children who were constantly parasitemic had $10.0 \mathrm{~g} / \mathrm{L}$ (95\% CI $3.3-$ 17.0) lower median $\mathrm{Hb}$ than those with $>2$ negative bloodslides during the five-month study period.

Malaria indices and $\mathrm{Hb}$. When combined, the malaria indices markedly affected individual median $\mathrm{Hb}$ in children $<$ 24 months (Table 4). For example, children with no clinical malaria episode and a geometric mean asymptomatic parasite density $<400 / \mu$ l had a median $\mathrm{Hb}$ of $104 \mathrm{~g} / \mathrm{L}$. This level decreased to $85 \mathrm{~g} / \mathrm{L}$ if at least one clinical malaria episode occurred and to $83 \mathrm{~g} / \mathrm{L}$ if the mean asymptomatic parasitemia increased to $\geq 400 / \mu l$. In case of both, the median $\mathrm{Hb}$ fell to $79 \mathrm{~g} / \mathrm{L}$. To reach a median $\mathrm{Hb}$ concentration $>100 \mathrm{~g} / \mathrm{L}$, children $<24$ months in this study had to have no clinical malaria episode, a mean parasitemia $<25$ parasites $/ \mu 1$, and at least two negative blood-slides. No cohort child $<24$ months had $\mathrm{Hb}>110 \mathrm{~g} / \mathrm{L}$ consistently, the Centers for Disease Control and Prevention (CDC) criterion for a normal $\mathrm{Hb}$ level. ${ }^{27}$

Cumulated parasitemia. The association between simultaneous parasite density and $\mathrm{Hb}$ was inconsistent; there was an association in the baseline survey, but not in the end survey, nor in each subject's first or only clinical malaria episode (data not shown). Similarly, the geometric mean symptomatic parasitemia and the occurrence of symptomatic parasitemias $>20,000 / \mu l$ did not influence the individual median $\mathrm{Hb}$ during the study period, even after adjusting for age and SP treatment. Furthermore, there was no association between baseline $\mathrm{Hb}$ and parasitemia in the first malaria episode, but baseline parasitemia was significantly related to $\mathrm{Hb}$ in the first malaria episode. To allow for a longer influ-

TABLE 3

Change in hemoglobin $(\mathrm{Hb})(\mathrm{g} / \mathrm{L})$ between Day 0 and Day 3 in each subject's first or only clinical falciparum malaria episode

\begin{tabular}{|c|c|c|c|}
\hline \multirow[b]{2}{*}{ Chloroquine treatment responses } & \multicolumn{3}{|c|}{$\begin{array}{l}\text { Change in Hb } 72 \text { hours } \\
\text { after starting chloroquine treatment, g/L (SE) }\end{array}$} \\
\hline & Parasitemia $<20,000 / \mu$ l on Day 0 & Parasitemia $\geq 20,000 / \mu \mathrm{l}$ on Day 0 & All \\
\hline Early treatment failures & $+1(3), n=4$ & $-17(3), n=6$ & $-10(4), n=10$ \\
\hline $\begin{array}{l}\text { Late treatment failure }+ \text { adequate clinical } \\
\text { responses }\end{array}$ & $-2(1), \mathrm{n}=25$ & $-3(2), \mathrm{n}=13$ & $-2(1), \mathrm{n}=38$ \\
\hline
\end{tabular}

$\mathrm{n}=$ number of patients. 


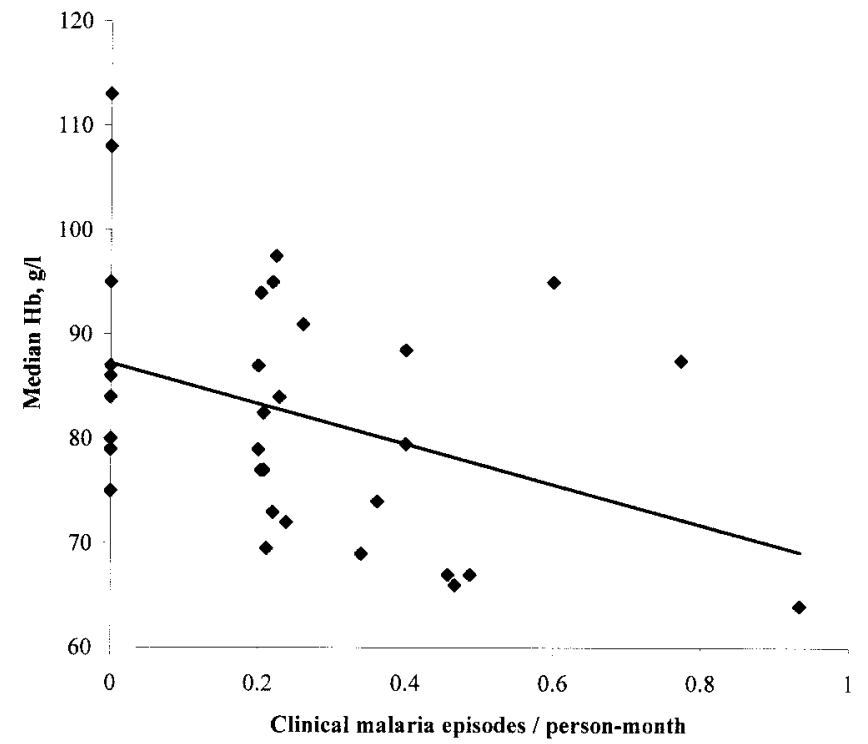

FigURE 1. Association between incidence of clinical malaria episodes and individual median $\mathrm{Hb}$ in children aged $<24$ months not fulfilling the criteria for chloroquine treatment failure and not receiving treatment with sulfadoxine-pyrimethamine (SP). Correlation coefficient, $\mathrm{r}=0.38 ; P=0.03$.

ence of parasitemia, each individual's parasite load over five months was estimated as the area under the parasitemia curve (AUPC) by multiplying the geometric mean of two consecutive parasite densities with number of days between measurements (Figure 3). Adjusting for age, the AUPC was highly significant in explaining the final $\mathrm{Hb}$ concentration. Using only asymptomatic, symptomatic, or cross-sectional parasitemia recordings produced a less satisfactory fit of the regression model.

Severe anemia. Severe anemia, defined as median $\mathrm{Hb}<$ $70 \mathrm{~g} / \mathrm{L}$, was recorded in 7 of 46 children aged $<24$ months despite optimal case management using local treatment guidelines. Children with severe anemia were unlikely to have had any negative blood-slides during the study, relative risk (RR) 0.3 (95\% CI 0.09-1.0). They had higher mean asymptomatic parasite density $(2,600 / \mu \mathrm{l})$ than children without severe anemia $(730 / \mu 1 ; P=0.01)$, and their mean clinical malaria incidence rate was $0.56 /$ person-month compared to $0.29(P=0.01)$.

Within-individual Hb fluctuations. The mean $\mathrm{Hb}$ improvement from study start to end in children without clinical malaria episodes was $2.1 \mathrm{~g} / \mathrm{L}$ in subjects $<24$ months and $1.2 \mathrm{~g} / \mathrm{L}$ in those $\geq 24$ months. The mean variation in individual $\mathrm{Hb}$ estimates during the study was $14 \mathrm{~g} / \mathrm{L}$ and $12 \mathrm{~g} /$ $\mathrm{L}$, respectively. Hence, in addition to a net increase in $\mathrm{Hb}$, there was substantial individual fluctuation in the repeated $\mathrm{Hb}$ estimates. Variation in $\mathrm{Hb}$ due to changes in parasitemia would presumably occur. The geometric mean within-individual variation in parasitemia in the same asymptomatic individuals was 4,200 (IQR 2,200-9,300) parasites/ $\mu 1$; this variation was, however, unrelated to fluctuations in $\mathrm{Hb}(P=$ $0.60)$. In contrast, the fluctuations in $\mathrm{Hb}$ were significantly related to episodes of both vomiting and diarrhea (data not shown).

\section{DISCUSSION}

To determine the influence of malaria parasitemia on $\mathrm{Hb}$ concentration, children in the present study were followed prospectively for five months in a clinical setting at village level under optimal local diagnostic and treatment conditions. Although mostly mild and moderate malaria cases abound at community level, such cases may precede severe disease manifestations, including severe anemia, that are seen in children admitted to hospital. Furthermore, it is probably more appropriate to study the basic interaction between parasite and host at community level since this interaction is less distorted by complicating factors, including antimalarial treatment before the onset of severe symptoms requiring hospitalization. In addition, a longitudinal perspective was considered essential when trying to capture a pathogenetic time-lag of the effects of parasitemia on $\mathrm{Hb}$.

Capillary $\mathrm{Hb}$ estimates in children are prone to pre-analytic variation and bias. ${ }^{28}$ In the present study, dehydration due to vomiting and diarrhea was associated with withinindividual fluctuations in $\mathrm{Hb}$ concentration. In addition, technical sampling bias may be a problem in children who are sick and less cooperative during capillary blood collection. To reduce the effects of methodological variability in repeated capillary $\mathrm{Hb}$ estimates, the median of an individual's $\mathrm{Hb}$ readings over five months was used. This value, reflecting the individual's long-term Hb-profile, was correlated with clinical and parasitological data collected during the study period. The overall five-month observation time extended well beyond the expected regeneration time of red blood cells, allowing for an $\mathrm{Hb}$ 'steady state' level to be reached under the present diagnostic and treatment conditions.

The differences in parasitemia and $\mathrm{Hb}$ between the baseline and end surveys probably reflect the intensified malaria case management during the study. The laboratory indices of children $\geq 24$ months were unchanged from study start to end, whereas those of children $<24$ months showed only modest improvement (Table 1). The continued high prevalence of parasitemia and low mean $\mathrm{Hb}$ levels at the end survey represent the end results of five months of prompt malaria case management in a holoendemic area. Whether the use of sulfadoxine-pyrimethamine instead of chloroquine as first-line treatment would have improved these results remains undetermined. However, the median $\mathrm{Hb}$ during the study remained unaffected by SP treatment, emphasizing its temporary impact on $\mathrm{Hb}$ levels. This, therefore, demonstrates the limitations of 'case management' as the only malaria control tool, using current treatment guidelines.

There was an excessive vulnerability to symptomatic malaria in the youngest children (Table 2). In addition, $40 \%$ of children $<18$ months were affected by early chloroquine treatment failure during the five months' observation period, leading to a concomitant drop in $\mathrm{Hb}$, especially following hyperparasitemia (Table 3). ${ }^{29}$ Hence, it was predominantly the youngest children who suffered attacks of severe acute hemolytic anemia. All treatment failures received prompt second-line therapy with SP, which at follow-up compensated for the immediate loss in $\mathrm{Hb}$, most likely by subsequent reduction in the asymptomatic parasitemia level and possibly clinical malaria incidence rate. Since the availability of ef- 

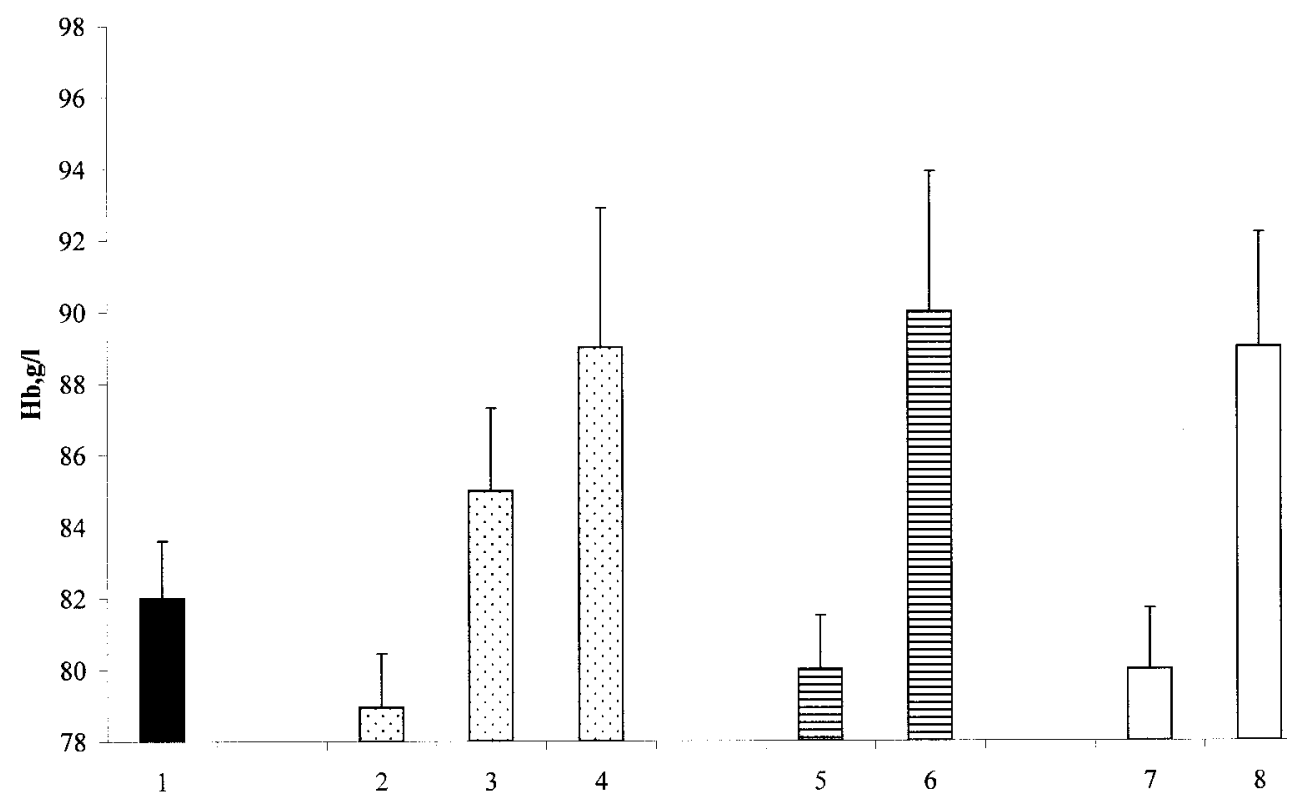

A
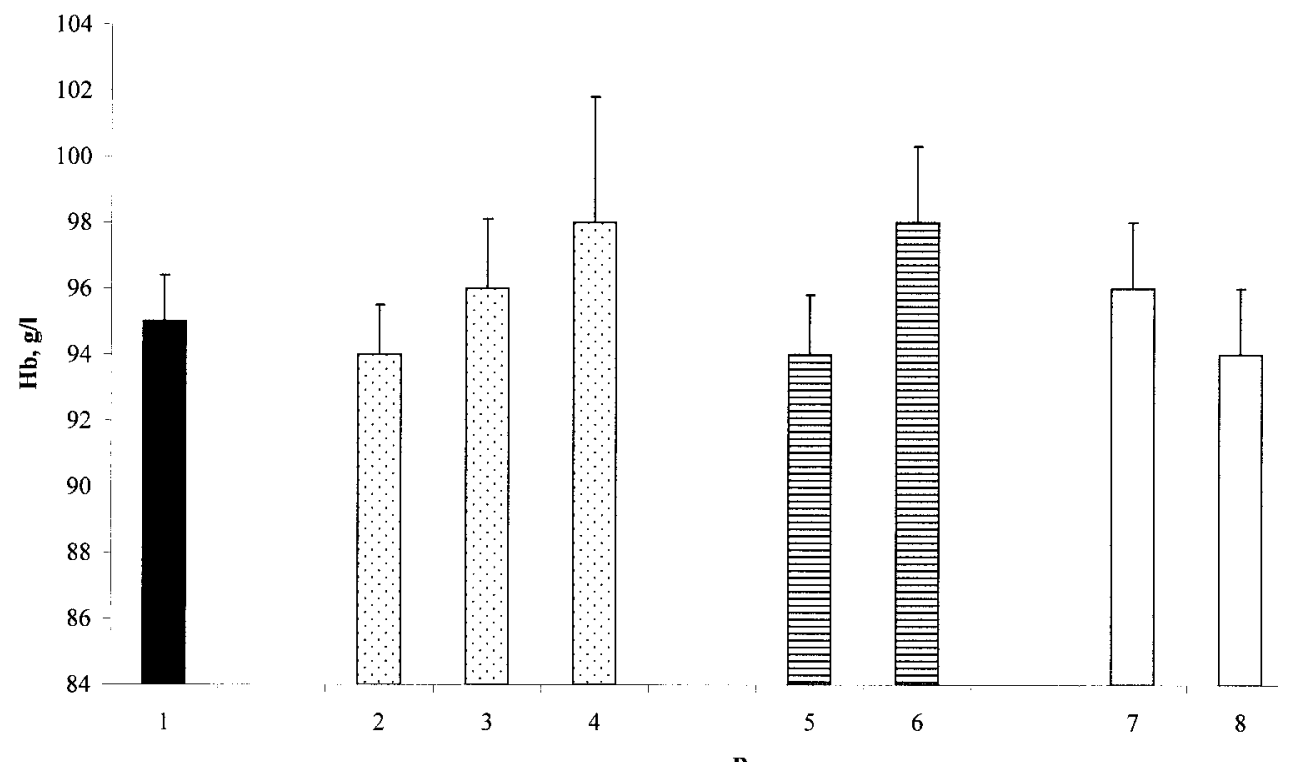

FIGURE 2. Effects of malaria parasitemia and clinical malaria episodes on mean of individual median $\mathrm{Hb}, \mathrm{g} / \mathrm{L}$ (SE). Figure A represents children aged $<24$ months at study-end and Figure B, children $\geq 24$ months.

Column $1=$ overall mean $\mathrm{Hb}$

Column 2 = no negative blood-slide

Column $3=\geq 1$ negative blood-slide

Column $4=>2$ negative blood-slides

Column $5=$ geometric mean asymptomatic parasitemia $\geq 400$ parasites $/ \mu l$

Column $6=$ geometric mean asymptomatic parasitemia $<400$ parasites $/ \mu 1$

Column $7=\geq 1$ clinical malaria episode

Column $8=$ no clinical malaria episodes

fective second-line antimalarial therapy at village level may be inconsistent under non-study conditions, it is likely that acute anemia due to early chloroquine treatment failure is a major preventable contributor of anemia currently observed in young children. Furthermore, chloroquine treatment, even without therapeutic failure, could not prevent a general reduction in $\mathrm{Hb}$ levels (Figure 1). It was not possible to determine whether this was due to cumulated recurrent loss of
$\mathrm{Hb}$ during the repeated malaria episodes per se, or to a higher post-treatment asymptomatic parasitemia level compared to SP.

There was a clear dose-response relationship between $P$. falciparum parasitemia and $\mathrm{Hb}$ in children younger than two years (Figure 2A). In addition, the $\mathrm{Hb}$ concentration at study-end was found to be a cumulative function of the previous parasitemias over five months, adjusting for age. In 
TABLE 4

Combined effects of malaria indices on mean of individual median hemoglobin ( $\mathrm{Hb}$ ) g/L (SE) in children $<24$ months old

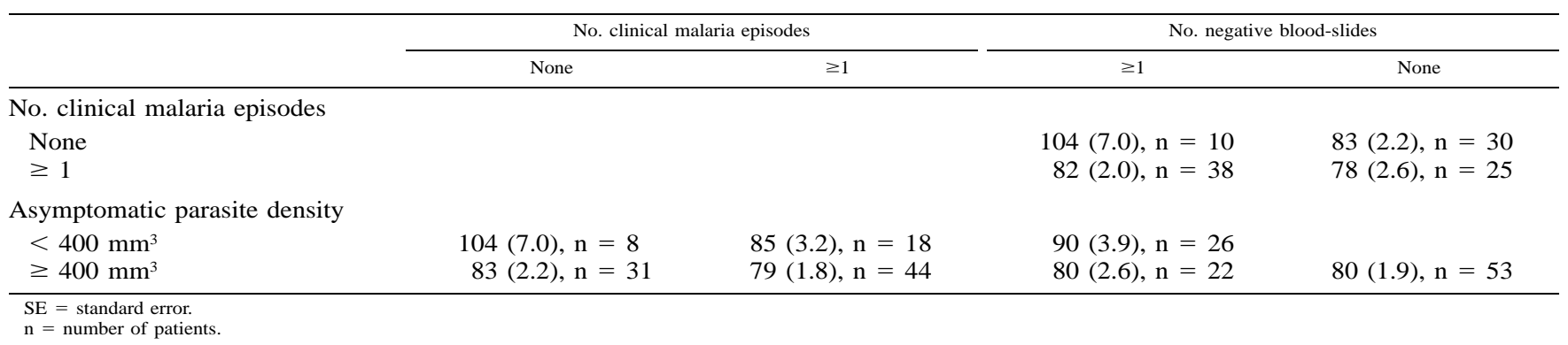

the formula for AUPC each symptomatic parasitemia was given a weight of three days, out of a total study duration of 140 days. The extension of duration of symptomatic parasitemias was prevented by immediate drug intervention in the case of treatment failure. In addition, logarithmic transformation of parasite counts further reduced the relative importance of high symptomatic parasite densities. Hence, in the sampling scheme used, symptomatic parasitemias were restricted both in time and magnitude compared to asymptomatic parasitemias. Considering the excellent model fit under this scheme, it seems plausible that asymptomatic para-

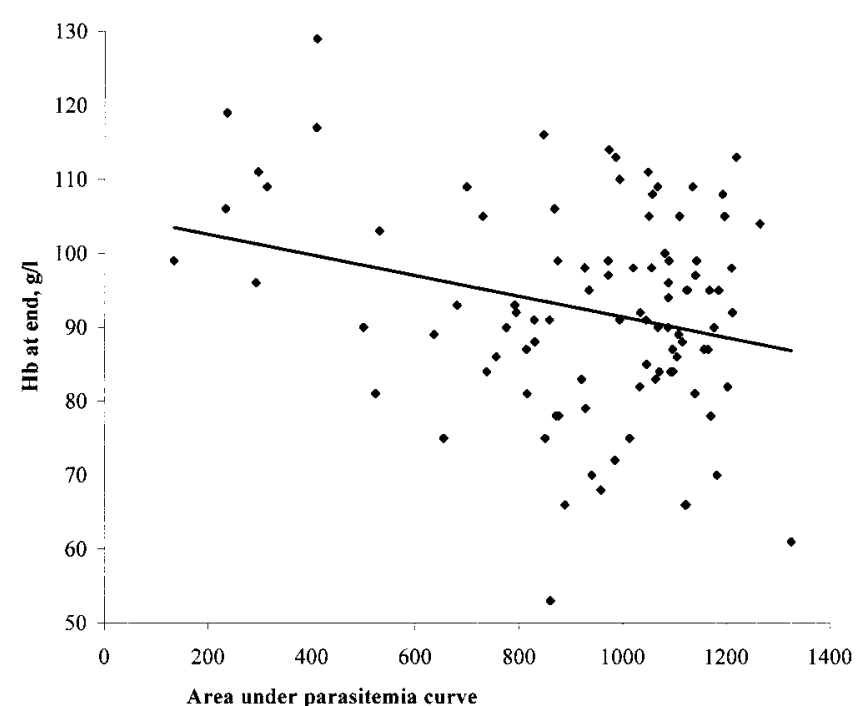

\begin{tabular}{|c|c|c|c|c|}
\hline Analysis of variance & Df & Sum of squares & F-ratio & Prob>F \\
\hline Model & 2 & 3,250 & 9.92 & 0.0001 \\
\hline Error & 94 & 15,400 & & \\
\hline Total & 96 & 18,650 & & \\
\hline Parameters & & & & \\
\hline AUPC & 1 & 1,187 & 7.25 & 0.008 \\
\hline Age & 1 & 2,004 & 12.2 & 0.0007 \\
\hline
\end{tabular}

FIGURE 3. Hemoglobin $(\mathrm{Hb})(\mathrm{g} / \mathrm{L})$ at study-end as a function of the area under parasitemia curve (AUPC) during five months. Adjusting for age, the attached table describes the regression procedure of $\mathrm{Hb}$ at end on AUPC and age. AUPC $=\Sigma\left[\left(D_{t+1}-D_{t}\right)\left(P_{t+1}+P_{t}\right) /\right.$ 2 ], where $\mathrm{D}=$ day and $\mathrm{P}=\log$ parasite density. sitemias were relatively more important than symptomatic parasite densities in determining the final $\mathrm{Hb}$ concentration.

Asymptomatic parasitemia may be beneficial in inducing and sustaining partial immunity against malaria. ${ }^{30}$ However, a significant drawback is the suppression of $\mathrm{Hb}$ concentration. The absolute and prolonged impact of asymptomatic parasitemia on $\mathrm{Hb}$ levels could not be determined since no child was aparasitemic over the full study period. Moreover, all cohort children $<24$ months were anemic. Hence, it was not possible to determine an asymptomatic parasitemia cutoff level which would hypothetically allow for semi-immunity to develop without leading to anemia. ${ }^{22}$

Hemoglobin levels only recovered when at least two of the measured malaria indices were ameliorated, i.e., when most of the malaria was eliminated (Table 4). This emphasizes the need for drugs to eliminate parasitemia for a certain period of time in order to improve anemia. ${ }^{31}$ From this perspective, antimalarial treatment with drugs of short duration, e.g., chlorproguanil-dapsone or artemisinine derivatives, may be less effective against anemia under perennial transmission conditions because of more frequent symptomatic or asymptomatic re-infections than after treatment with drugs that are slowly eliminated. Even if such re-infections are adequately treated when symptomatic, there may be difficulties in restoring long-term $\mathrm{Hb}$ concentration, particularly in children $<24$ months. Similarly, recurrent antimalarial drug treatment in small children with parasitemia, but no fever, may be successful in preventing anemia if performed with an antimalarial with relatively long action time, e.g., SP. ${ }^{14,32}$ However, the effects of such repeated abortion of chronic asymptomatic parasitemia on the development of partial antimalarial immunity need to be considered. ${ }^{33,34}$

At study-end, the prevalence of parasitemia in children $<$ 24 months old was lower than in those $\geq 24$ months (Table 1). This possibly reflected the frequent use of SP treatment in small children, although $\mathrm{Hb}$ was lower in children $<24$ months at study-end. This may be related to the fact that young children are more prone to develop anemia as a complication to malaria than their older peers. However, in the regression model of Figure 3, the two-way interaction term between age and parasitemia was not significant (data not shown), suggesting that at similar levels of parasitemia, the effect on $\mathrm{Hb}$ did not differ between ages. However, young age per se was also related to lower $\mathrm{Hb}$, and since parasite densities are highest in youngest children, anemia in this age group may be an independent but additive result of low age and high parasite densities. In addition to malaria, other age- 
related factors, e.g., iron deficiency or other infections, may also contribute to anemia. Hookworm infection, however, was rare and not related to $\mathrm{Hb}$ levels in this study, consistent with the age-dependent acquirement of infection. ${ }^{35}$ Light hookworm infections have been implicated as a cause of anemia in populations with poor iron status, but in children $<3$ years, hookworm egg counts rarely reach the concentration known to affect $\mathrm{Hb}$ concentration. ${ }^{3,5}$ Although additional stool samples may have detected a few more infected children, in this cohort of anemic children hookworm infection was most likely of inferior importance.

In conclusion, our data from an area of high malaria transmission show that anemia in early childhood is highly associated to falciparum malaria but that the $\mathrm{Hb}$ value is influenced by several partly independent factors, i.e., a cumulative effect by continuous asymptomatic parasitemia, and an acute effect by a clinical episode, especially in connection with treatment failure. Prompt malaria case management, including sulfadoxine-pyrimethamine as a second-line drug, appears to restore short-term $\mathrm{Hb}$ values but does not, on its own, sufficiently improve the long-term $\mathrm{Hb}$ levels in children below 24 months of age.

Financial support: This study was funded by the Swedish International Development Agency with additional support from R\&E Lundstrom minne foundation.

Authors' addresses: Hakan Ekvall and Anders Bjorkman, Unit of Infectious Diseases, Karolinska Institute at Karolinska Hospital, 171 76 Stockholm, Sweden. Zul Premji, Department of Parasitology and Entomology, Muhimbili University College of Health Sciences, PO Box 65011, Dar es Salaam, Tanzania. Steve Bennett, Tropical Epidemiology Group, Department of Infectious and Tropical Diseases, London School of Tropical Medicine and Hygiene, Keppel St, London WC1E 7HT, United Kingdom.

Reprint requests: Hakan Ekvall, Unit of Infectious Diseases, Karolinska Institute at Karolinska Hospital, 17176 Stockholm, Sweden. E-mail: hakekv@ki.se

\section{REFERENCES}

1. Lackritz EM, Campbell CC, Ruebush TKD, Hightower AW, Wakube W, Steketee RW, Were JB, 1992. Effect of blood transfusion on survival among children in a Kenyan hospital. Lancet 340: 524-528.

2. Phillips RE, Pasvol G, 1992. Anaemia of Plasmodium falciparum malaria. Baillieres Clin Haematol 5: 315-330.

3. Brooker S, Peshu N, Warn PA, Mosobo M, Guyatt HL, Marsh K, Snow RW, 1999. The epidemiology of hookworm infection and its contribution to anaemia among pre-school children on the Kenyan coast. Trans $R$ Soc Trop Med Hyg 93: 240-246.

4. Sturrock RF, Kariuki HC, Thiongo FW, Gachare JW, Omondi BG, Ouma JH, Mbugua G, Butterworth AE, 1996. Schistosomiasis mansoni in Kenya: relationship between infection and anaemia in schoolchildren at the community level. Trans $R$ Soc Trop Med Hyg 90: 48-54.

5. Tatala S, Svanberg U, Mduma B, 1998. Low dietary iron availability is a major cause of anemia: a nutrition survey in the Lindi District of Tanzania. Am J Clin Nutr 68: 171-178.

6. Alonso PL, Lindsay SW, Armstrong Schellenberg JR, Keita K, Gomez P, Shenton FC, Hill AG, David PH, Fegan G, Cham $\mathrm{K}$, et al., 1993. A malaria control trial using insecticide-treated bed nets and targeted chemoprophylaxis in a rural area of The Gambia, West Africa. 6. The impact of the interventions on mortality and morbidity from malaria. Trans $R$ Soc Trop Med Hyg 87 Suppl 2: 37-44.

7. Greenwood BM, Bradley AK, Greenwood AM, Byass P, Jam- meh K, Marsh K, Tulloch S, Oldfield FS, Hayes R, 1987. Mortality and morbidity from malaria among children in a rural area of The Gambia, West Africa. Trans $R$ Soc Trop Med Hyg 81: 478-486.

8. Menendez C, Kahigwa E, Hirt R, Vounatsou P, Aponte JJ, Font F, Acosta CJ, Schellenberg DM, Galindo CM, Kimario J, Urassa H, Brabin B, Smith TA, Kitua AY, Tanner M, Alonso PL, 1997. Randomised placebo-controlled trial of iron supplementation and malaria chemoprophylaxis for prevention of severe anaemia and malaria in Tanzanian infants. Lancet 350: 844-850.

9. Miller LH, Good MF, Milon G, 1994. Malaria pathogenesis. Science 264: 1878-1883.

10. Achidi EA, Salimonu LS, Asuzu MC, Berzins K, Walker O, 1996. Studies on Plasmodium falciparum parasitemia and development of anemia in Nigerian infants during their first year of life. Am J Trop Med Hyg 55: 138-143.

11. Kitua AY, Smith T, Alonso PL, Masanja H, Urassa H, Menendez C, Kimario J, Tanner M, 1996. Plasmodium falciparum malaria in the first year of life in an area of intense and perennial transmission. Trop Med Int Health 1: 475-484.

12. Snow RW, Nahlen B, Palmer A, Donnelly CA, Gupta S, Marsh K, 1998. Risk of severe malaria among African infants: direct evidence of clinical protection during early infancy. $J$ Infect Dis 177: 819-822.

13. Redd SC, Wirima JJ, Steketee RW, 1994. Risk factors for anemia in young children in rural Malawi. Am J Trop Med Hyg 51: $170-174$.

14. Zucker JR, Perkins BA, Jafari H, Otieno J, Obonyo C, Campbell CC, 1997. Clinical signs for the recognition of children with moderate or severe anaemia in western Kenya. Bull World Health Organ 75: 97-102.

15. Greenwood BM, 1987. Asymptomatic malaria infections-do they matter? Parasitol today 3: 206-214.

16. Newton CR, Warn PA, Winstanley PA, Peshu N, Snow RW, Pasvol G, Marsh K, 1997. Severe anaemia in children living in a malaria endemic area of Kenya. Trop Med Int Health 2: $165-178$.

17. Trape JF, Rogier C, Konate L, Diagne N, Bouganali H, Canque B, Legros F, Badji A, Ndiaye G, Ndiaye P, Brahimini K, Ousmane F, Druilhe P, da Silva LP, 1994. The Dielmo project: a longitudinal study of natural malaria infection and the mechanisms of protective immunity in a community living in a holoendemic area of Senegal. Am J Trop Med Hyg 51: 123137.

18. Hedberg K, Shaffer N, Davachi F, Hightower A, Lyamba B, Paluku KM, Nguyen-Dinh P, Breman JG, 1993. Plasmodium falciparum-associated anemia in children at a large urban hospital in Zaire. Am J Trop Med Hyg 48: 365-371.

19. Abdalla S, Weatherall DJ, Wickramasinghe SN, Hughes $M$, 1980. The anaemia of $P$. falciparum malaria. $B r J$ Haematol 46: $171-183$.

20. Slutsker L, Taylor TE, Wirima JJ, Steketee RW, 1994. In-hospital morbidity and mortality due to malaria-associated severe anaemia in two areas of Malawi with different patterns of malaria infection. Trans $R$ Soc Trop Med Hyg 88: 548-551.

21. Phillips RE, Looareesuwan S, Warrell DA, Lee SH, Karbwang J, Warrell MJ, White NJ, Swasdichai C, Weatherall DJ, 1986. The importance of anaemia in cerebral and uncomplicated falciparum malaria: role of complications, dyserythropoiesis and iron sequestration. $Q J$ Med 58: 305-323.

22. Kitua AY, Smith TA, Alonso PL, Urassa H, Masanja H, Kimario J, Tanner M, 1997. The role of low level Plasmodium falciparum parasitaemia in anaemia among infants living in an area of intense and perennial transmission. Trop Med Int Health 2: 325-333.

23. Ekvall H, Premji Z, Bjorkman A, 2000. Micronutrient and iron supplementation and effective antimalarial treatment synergistically improve childhood anemia. Trop Med Int Health 5: 696-705.

24. WHO, 1996. Assessment of therapeutic efficacy of antimalarial drugs for uncomplicated falciparum malaria in areas with intense transmission. Geneva: World Health Organization. 
25. WHO, 1991. Basic Malaria Microscopy. Part I. Learner's Guide. Geneva: World Health Organization.

26. Ash LR, Orihel TC, 1987. Parasites: A Guide to Laboratory Procedures and Identification. Chicago, IL: ASCP Press.

27. CDC, 1989. CDC criteria for anemia in children and childbearing-aged women. MMWR 38: 400-403.

28. Annesley TM, 1994. Analytical test variables. McClatchey KD, ed. Clinical Laboratory Medicine. Baltimore, MD: Williams \& Wilkins Press, 77-95.

29. Ekvall H, Premji Z, Bjorkman A, 1998. Chloroquine treatment for uncomplicated childhood malaria in an area with drug resistance: early treatment failure aggravates anaemia. Trans $R$ Soc Trop Med Hyg 92: 556-560.

30. Greenwood B, Marsh K, Snow R, 1991. Why do some African children develop severe malaria? Parasitol Today 7: 277-281.

31. Bloland PB, Lackritz EM, Kazembe PN, Were JB, Steketee R, Campbell CC, 1993. Beyond chloroquine: implications of drug resistance for evaluating malaria therapy efficacy and treatment policy in Africa. J Infect Dis 167: 932-937.
32. Shulman CE, Dorman EK, Cutts F, Kawuondo K, Bulmer JN, Peshu N, Marsh K, 1999. Intermittent sulphadoxine-pyrimethamine to prevent severe anaemia secondary to malaria in pregnancy: a randomised placebo-controlled trial. Lancet 353: 632-636.

33. Greenwood BM, David PH, Otoo-Forbes LN, Allen SJ, Alonso PL, Armstrong Schellenberg JR, Byass P, Hurwitz M, Menon A, Snow RW, 1995. Mortality and morbidity from malaria after stopping malaria chemoprophylaxis. Trans $R$ Soc Trop Med Hyg 89: 629-633.

34. Fraser-Hurt N, Felger I, Edoh D, Steiger S, Mashaka M, Masanja H, Smith T, Mbena F, Beck HP, 1999. Effect of insecticide-treated bed nets on haemoglobin values, prevalence and multiplicity of infection with Plasmodium falciparum in a randomized controlled trial in Tanzania. Trans $R$ Soc Trop Med Hyg 93 Suppl 1: 47-51.

35. Stoltzfus RJ, Albonico M, Chwaya HM, Savioli L, Tielsch J, Schulze K, Yip R, 1996. Hemoquant determination of hookworm-related blood loss and its role in iron deficiency in African children. Am J Trop Med Hyg 55: 399-404. 